\title{
Global warming impact on confined livestock in buildings: efficacy of adaptation measures to reduce heat stress for growing-fattening pigs
}

\author{
Günther Schauberger ${ }^{1}$ (D) Christian Mikovits ${ }^{1} \cdot$ Werner Zollitsch $^{2}$ • \\ Stefan J. Hörtenhuber ${ }^{2}$. Johannes Baumgartner ${ }^{3} \cdot$ Knut Niebuhr $^{3} \cdot$ Martin Piringer $^{4}$. \\ Werner Knauder ${ }^{4}$. Ivonne Anders ${ }^{5} \cdot$ Konrad Andre $^{5} \cdot$ Isabel Hennig-Pauka ${ }^{6}$. \\ Martin Schönhart ${ }^{7}$
}

Received: 9 October 2018 / Accepted: 8 August 2019/Published online: 21 August 2019

(C) The Author(s) 2019

\begin{abstract}
Pigs and poultry are raised predominantly at high stocking densities in confined, insulated livestock buildings with mechanical ventilation systems. These systems are quite sensitive to heat stress, which has increased in recent decades from anthropogenic warming. A dataset of hourly meteorological data from 1981 to 2017 was used to drive a steady-state balance model for sensible and latent heat that simulates the indoor climate of a conventional reference system, and this model was used to predict the effect of global warming on growing-fattening pigs housed in such livestock confinement buildings. Seven adaptation measures were selected to investigate the effect on the indoor climate; these measures included three energy-saving air preparation systems, a doubling of the maximum ventilation rate, a reduction in the stocking density, and a shift in the feeding and resting time patterns. The impact of heat stress on animals was calculated with the following three heat stress metrics: a threshold of the indoor temperature, the temperature-humidity index, and a body mass-adapted temperature. The seven adaptation measures were quantified by a reduction in factors of the heat stress parameters. The highest reduction of heat stress in comparison with the conventional reference system was achieved by the three air preparation systems in the range of 54 to $92 \%$ for adiabatic systems and 65 to $100 \%$ for an earth-air heat exchanger, followed by an increase in the ventilation rate and the time shift. The reduction in the stocking density showed the lowest improvement. In addition to the reduction in the heat stress, a temporal trend over three decades was also used to quantify the resilience of pig confinement systems. The efficacy of some of the adaptation measures is great enough to mitigate the increase of heat stress that occurs due to global warming.
\end{abstract}

Günther Schauberger

gunther.schauberger@vetmeduni.ac.at

Extended author information available on the last page of the article 


\section{Introduction}

Pig and poultry production occurs predominantly inside livestock confinement buildings, which are often referred to as industrial systems (Gerber et al. 2013). These systems are characterised by a mechanical ventilation system, high stocking density, and insulated buildings. The increase of heat stress in recent decades for farm animals due to the anthropogenic warming is well known, especially in livestock confinement buildings. These global warming effects are relevant not only from an animal welfare perspective (Huynh et al. 2005) but also from an economic point of view (St-Pierre et al. 2003).

Rötter and van de Geijn (1999) assumed that the vulnerability of industrial and confined livestock systems by global warming is lower than that of alternative outdoor (grazing) systems due to the opportunity of the application of adaptation measures (AMs). Alternatively, Mikovits et al. (2019) showed that, for Central Europe, the indoor climate of livestock confinement systems is more sensible to heat stress compared with the outdoor situation, with increasing trends observed in the frequency and duration of heat stress over the past three decades. This sensitivity is caused primarily by the higher indoor temperatures compared with outdoor temperatures, even in summer, due to the highly sensitive heat load by the animals. St. Pierre et al. (2003) analysed the economic impact of heat stress in the US livestock industry for past climate situations and revealed billion dollar losses, with substantial spatial heterogeneity across US regions. Hence, global warming may affect requirements for the control of thermal conditions of livestock buildings, such as their mechanical ventilation systems (Olesen and Bindi 2002). This calls for AMs to reduce the existing, as well as the upcoming, increase in heat stress and its impact on welfare, health, and productivity. The application of AMs will increase the costs (e.g., running costs, energy, and investment) of intensive livestock production systems, which should be balanced by their effects on livestock productivity and animal welfare.

The AMs can be divided into two groups. The first group modifies the sensible and latent heat balance of the building by cooling the inlet air, reducing the sensible and latent heat release, and modifying the thermal properties of the building. The second group influences the immediate thermal vicinity of the animals. Examples for such AMs are floor cooling (conductive cooling) (Bull et al. 1997; Cabezon et al. 2017; Silva et al. 2009), higher air velocity at the animal level to increase the convective heat release (wind-chill effect) (e.g., by tunnel ventilation, booster fans, and hybrid ventilation systems) (Zhang and Bjerg 2017), radiative cooling by a cooled cover of the laying zone (Pang et al. 2010), cooled drinking water (Jeon et al. 2006; Renaudeau et al. 2012), wallows (Bracke 2011; de Mello et al. 2017), or water baths (Huynh et al. 2006). The AMs of the first group can be evaluated by simulation models at the housing level, whereas the second group needs models at the animal level, which describe the heat release and the thermal regulation for individual animals.

A couple of these AMs were investigated by measurements at the farm level or for prototypes on a laboratory scale with the disadvantage that such measurements can be biased. Biases are caused by the variability of the meteorological situations on a year-to-year basis, the high variability of relevant parameters (e.g., live mass of animals 30 to $120 \mathrm{~kg}$ ), and the short duration of such measurements over a limited number of fattening periods. Such episodical research activities are often presented in a statistical way. Modelling approaches using such sources can lead to a more universally valid understanding, which can be transferred to other livestock systems (e.g., the body mass of the animals and various design values of the building and ventilation system) and climate regions (e.g., Cooper et al. 1998; Schauberger et al. 1999). 
In our investigation, we selected a steady-state simulation model of the indoor climate (Mikovits et al. 2019; Schauberger et al. 2000) and applied it to a typical livestock building for growing-fattening pigs in Central Europe. On the basis of such model calculations, the multidecadal temporal trend of the thermal climate inside livestock buildings can be calculated. It is an indicator of future global warming impacts. The objective of the study is to estimate the temporal trend of the thermal conditions inside livestock buildings for growing-fattening pigs for a conventional reference system relative to heat stress. This situation will be compared with various AMs and their related efficacies. The results from a period of 37 years, particularly for extreme years, should indicate which of the AMs will be appropriate for reducing heat stress for growing-fattening pigs under future climate conditions.

\section{Materials and methods}

\subsection{Meteorological data}

For the calculation of the indoor air conditions, such as air temperature and humidity, meteorological data are needed on an hourly basis. The Austrian Meteorological Service ZAMG (Zentralanstalt für Meteorologie und Geodynamik) compiled a reference time series on the basis of representative observational sites around the city of Wels $\left(48.16^{\circ} \mathrm{N}, 14.07^{\circ} \mathrm{E}\right)$ for the period 1981 to 2017, with a temporal resolution of $1 \mathrm{~h}$. Following the climate classification of Köppen and Geiger (c.f. Kottek et al. 2006), the station is located within class $\mathrm{Cfb}$ (warm temperate, fully humid, and warm summer), which is representative for large areas in Central Europe, excluding the Alps. Compared with the reference period of 19712000 for the whole province of Upper Austria, a future mean increase of temperature is expected with values of approximately $+1.4^{\circ} \mathrm{C}\left(\sim \pm 0.5^{\circ}\right)$ until the middle of the century. For the region around Wels, the number of summer days (daily maximum temperature $\geq 25^{\circ} \mathrm{C}$ ) will increase from $43.3 \mathrm{~d} \mathrm{a}^{-1}$ by 14.4 additional days (increase of \pm 4.5 days decade ${ }^{-1}$ ), and the number of hot days (daily maximum temperature $\geq 30^{\circ} \mathrm{C}$ ) of $5.3 \mathrm{~d} \mathrm{a}^{-1}$ will increase by 7 to 13 $\mathrm{d} \mathrm{a}^{-1}$ in the middle of the century (Chimani et al. 2016).

\subsection{Indoor climate model of a pig building}

The indoor climate of the pig building was simulated by a steady-state model which calculates the thermal indoor parameters (air temperature and humidity) and the ventilation flow rate. The thermal environment inside the building depends on the sensible and latent heat release of the animals, the thermal properties of the building, and the ventilation system and its control unit. The core of the model is the calculation of the sensible heat balance of a livestock building (Mikovits et al. 2019; Schauberger et al. 1999, 2000). The model calculation was performed for a typical livestock building for fattening pigs for Central Europe for 1800 heads, divided into 9 sections, with 200 animals each. The system parameters, which describe the conventional reference system REF (properties of the livestock, building, and mechanical ventilation system), are summarised in Table 1.

The minimum and maximum volume flow rates were determined by the CIGR (1989).

For an all in/all out production system, an animal growth model describes the increase of the release of energy and $\mathrm{CO}_{2}$ by the growing mass of the animals in the herd. The time course of the body mass of growing-fattening pigs behaves like a sawtooth wave, with one fattening 
Table 1 System parameters for livestock, building, and ventilation system related to one animal place for the indoor climate simulation of the conventional reference system REF

\begin{tabular}{|c|c|}
\hline Parameter & Value \\
\hline \multicolumn{2}{|l|}{ Animal } \\
\hline Body mass $m$ & $30-120 \mathrm{~kg}$ \\
\hline Service period (building emptied for cleaning and disinfection) & 10 days \\
\hline \multicolumn{2}{|l|}{ Building } \\
\hline Area of the building oriented to the outside (ceiling, walls, windows) & $1.41 \mathrm{~m}^{2}$ \\
\hline $\begin{array}{l}\text { Mean thermal transmission coefficient } U \text { weighted by the area of the construction } \\
\text { elements (wall, ceiling, door, and windows) which are oriented to the outside }\end{array}$ & $0.41 \mathrm{~W} \mathrm{~m}^{-2} \mathrm{~K}^{-1}$ \\
\hline \multicolumn{2}{|l|}{ Ventilation system } \\
\hline Set point temperature of the ventilation control unit, $T_{\mathrm{C}}$ & $16-20^{\circ} \mathrm{C}$ \\
\hline Proportional range (bandwidth) of the control unit, $\Delta T_{\mathrm{C}}$ & $4 \mathrm{~K}$ \\
\hline $\begin{array}{l}\text { Minimum volume flow rate of the ventilation system, } V_{\min } \text {, for maximum } \mathrm{CO}_{2} \\
\text { concentration } 3000 \mathrm{ppm} \text { and a body mass } m=30 \mathrm{~kg}\end{array}$ & $8.62 \mathrm{~m}^{3} \mathrm{~h}^{-1}$ \\
\hline $\begin{array}{l}\text { Maximum volume flow rate, } V_{\max } \text {, by maximum temperature difference between } \\
\text { indoor and outdoor of } 3 \mathrm{~K} \text { and a body mass } \mathrm{m}=120 \mathrm{~kg}\end{array}$ & $107 \mathrm{~m}^{3} \mathrm{~h}^{-1}$ \\
\hline
\end{tabular}

period of 118 days (approximately 1/3 of a year). These growth periods are superimposed and interact with the time course of the outdoor temperature. To create statistically valid results, we calculated the body mass on the basis of a Monte Carlo method, called inverse transform sampling, a useful method for environmental sciences (e.g., Schauberger et al. 2013; Wilks 2011). Details of the method can be found in Mikovits et al. (2019).

\subsection{Heat stress parameters for growing-fattening pigs}

The heat stress for farm animals was quantified by three parameters. Two parameters of heat stress are constant values over the fattening period: (1) the indoor (dry bulb) air temperature $T$ and (2) the temperature-humidity index THI (Vitt et al. 2017) (Table 2). The third heat stress parameter considers the animal growth. To adapt the heat stress parameters to the needs of the growing pigs (30 to $120 \mathrm{~kg}$ ), the exceedance of the controllable temperature range was used with the limit value $X_{T U}=T_{\mathrm{c}}+\Delta T_{\mathrm{C}}$, depending on the set point temperature of the ventilation control unit $T_{\mathrm{c}}$, which is related to the body mass $m$ of the pigs between 16 and $20^{\circ} \mathrm{C}$ and the bandwidth of the control unit $\Delta T_{\mathrm{C}}$ (Table 1). When the indoor air temperature $T>X_{T U}$, the maximum ventilation flow rate is transported by the ventilation system. This body massadapted heat stress parameter $\left(X_{T U}\right)$ lies in the range between $24{ }^{\circ} \mathrm{C}$ at the beginning $(m=$ $30 \mathrm{~kg})$ and $20^{\circ} \mathrm{C}$ at the end $(m=120 \mathrm{~kg})$ of the fattening period and was defined according to Turnpenny et al. (2001).

For a time series with the length $t$ and $n$ equidistant observations of a selected parameter $x$, the exceedance frequency of a preselected threshold $X$ was defined by $P_{X}=\operatorname{prob}\{x \mid x>X\}$, given in hours per year $\left(\mathrm{h} \mathrm{a}^{-1}\right)$. The exceedance area (area under the curve) $A_{X}$ of a preselected threshold $X$ is calculated according to Thiers and Peuportier (2008) as follows:

$$
A_{X}=\sum_{i} \mid \begin{gathered}
x_{i}-X \text { for } x_{i}>X \\
0 \text { for } x_{i} \leq X
\end{gathered}
$$

The exceedance area above the threshold $X$ is defined analogously to the degree days (Gosling et al. 2013) but with the selected parameter $x_{i}$ being used on an hourly basis instead of daily mean values, with the results in $\mathrm{Kh} \mathrm{a}^{-1}$ for the air temperature (temperature difference is given 
Table 2 Heat stress parameters and the related threshold values $X$ (upper limit for specific physiological reactions) for pigs used to evaluate the indoor climate using the temperature $T\left({ }^{\circ} \mathrm{C}\right)$, the temperature-humidity index THI (-), and the body mass-adapted air temperature defined by the upper temperature limit of the controllable range $T_{T U}$ (Vitt et al. 2017)

\begin{tabular}{ll}
\hline Heat stress parameter & Threshold $X$ \\
\hline Constant heat stress parameters & \\
Air temperature $T\left({ }^{\circ} \mathrm{C}\right)$ & $X_{T}=25{ }^{\circ} \mathrm{C}$ \\
Temperature-Humidity Index $T H I$ & $X_{T H I}=75$ (alert situation) \\
$T H I=0.72 T_{\mathrm{DB}}+0.72 T_{\mathrm{WB}}+40.6$ & \\
Body mass-adapted heat stress parameter & $X_{T U}=T_{\mathrm{c}}+\Delta T_{\mathrm{C}}$ \\
Upper temperature limit of the controllable range $T_{T U}$ & \\
\hline
\end{tabular}

Dry bulb temperature $T_{\mathrm{DB}}$ (= indoor air temperature $T$ ); wet bulb temperature $T_{\mathrm{WB}}$; set point temperature of the control unit $T_{\mathrm{C}}$, decreasing with the body mass of the pigs $\left(20\right.$ to $\left.16^{\circ} \mathrm{C}\right)$; bandwidth $\Delta T_{\mathrm{C}}=4 \mathrm{~K}$

in $\mathrm{K}$ (Kelvin)) and $\mathrm{h} \mathrm{a}^{-1}$ for the $T H I$ (because $T H I$ is dimensionless). All parameters describing heat stress in pigs were calculated as annual sums over the 37-year period (1981-2017), as suggested by Hatfield et al. (2018).

\subsection{Model calculations and sensitivity analysis}

The model calculations were performed for the entire growing-fattening period for a body mass between 30 and $120 \mathrm{~kg}$. The calculations were performed for the period 1981 to 2017 to determine the trend for the 37 years. Additionally, we selected the years 1984 and 2003, as one of the coldest and warmest years, respectively, for summertime measures in recent decades, to show specific results outside of the trend calculations.

The temporal trend of the heat stress parameters is estimated with a linear function over time $t$ by $x_{\text {trend }}=k t+a$ with the linear trend (slope) $k$.

For all seven AMs and the selected heat stress parameters of air temperature, temperaturehumidity index, and body mass-adapted air temperature, the mean relative reduction of heat stress $R$ (in \%) was calculated for the exceedance frequency $P_{X}$ and the exceedance area $A_{X}$ relative to the REF system

$$
R_{P_{X}}=1-\sum_{i=1981}^{2017} \frac{P_{\mathrm{AM}, i}}{P_{\mathrm{REF}, i}} \text { and } R_{A_{X}}=1-\sum_{i=1981}^{2017} \frac{A_{\mathrm{AM}, i}}{A_{\mathrm{REF}, i}}
$$

With the time lag $T L$ in years, the retardation was calculated, which can be achieved by a certain AM to keep the heat stress at the level of 1981. The time lag was calculated on the basis of the linear trend

$$
T L=\frac{Y_{\mathrm{REF}, 1981}-Y_{\mathrm{AM}, 1981}}{k_{\mathrm{AM}}}
$$

with a certain heat stress parameter (exceedance frequency or exceedance area) for the reference system $Y_{\mathrm{REF}, 1981}$ and for a certain AM $Y_{\mathrm{AM}, 1981}$, calculated by the linear trend for 1981 and the slope of the selected AM $k_{\mathrm{AM}}$. The $T L$ was calculated for all seven AMs and the six heat stress parameters. 


\subsection{Adaptation measures}

For the AMs, three different energy-saving air preparation systems were investigated (Vitt et al. 2017): the direct evaporative cooling by cooling pads (CP), an indirect evaporative cooling by the combination of cooling pads with a regenerative heat exchanger (HE), and an earth-air heat exchanger (EAHE). Two further AMs modify the management of the livestock building by a reduction of the stocking density and corresponding heat release of the livestock during the summer period and by a shift of the diurnal variation due to a shift of the feeding and resting times by half a day. Another measure affects the design value of the ventilation system by doubling the maximum volume flow rate. Details on all seven AMs are presented below.

\subsubsection{Direct evaporative cooling: cooling pads}

In livestock confinement buildings, direct evaporative cooling devices are used to convert sensible heat (air temperature) via evaporation of water into latent heat (humidity) with the major goal to reduce the inlet air temperature. We assume cellulose as a matrix to increase the wet surface area. The efficacy of the $\mathrm{CP} \eta_{\mathrm{CP}}$, also called wet bulb depression efficacy (ASHRAE 2009), is expressed by

$$
\eta_{\mathrm{CP}}=\frac{T_{\text {out }}-T_{\mathrm{CP}}}{T_{\text {out }}-T_{\text {out }, \mathrm{WB}}} 100 \%
$$

with the outside air temperature (dry bulb) entering the $\mathrm{CP} T_{\text {out }}$, the air temperature leaving the $\mathrm{CP}$ entering the livestock building as inlet air $T_{\mathrm{CB}}$, and the wet bulb temperature of the outside air $T_{\text {out,WB}}$. For the calculation, we assumed $\eta_{\mathrm{CP}}=80 \%$ according to Fehr et al. (1983). Details can be found in Vitt et al. (2017).

\subsubsection{Indirect evaporative cooling: cooling pads combined with a regenerative heat exchanger CPHE}

Indirect evaporative cooling systems result in a reduction of the inlet air temperature by evaporation without humidification. The outside air is cooled using direct evaporative cooling. Then, this evaporatively cooled secondary air cools the outside air in a conventional air-to-air heat exchanger. We assumed CP and a downstream HE with a constant sensible efficiency of $\eta_{\mathrm{CP}}=80 \%$ and $\eta_{\mathrm{HE}}=65 \%$ (ASHRAE 2008), respectively, as shown in Fig. 1 . An overview of various versions of indirect cooling methods was given by Porumb et al. (2016a, b). Sax et al. (2012) showed the applicability for livestock buildings.

\subsubsection{Earth-air heat exchanger}

EAHEs utilise the ground as heat storage. Outside air flows through tubes with diameter $D$ in a range between 0.1 and $1.0 \mathrm{~m}$ and with length $L$ between 20 and $200 \mathrm{~m}$, buried to depth $z$ between 1 and $3 \mathrm{~m}$. EAHEs are well-investigated and tested practical energy-saving air treatment devices. The performance, i.e., the air temperature and humidity at the ends of the tubes, depends on the soil temperature, the outside air temperature and humidity, the thermal 
Cooling Pads CP

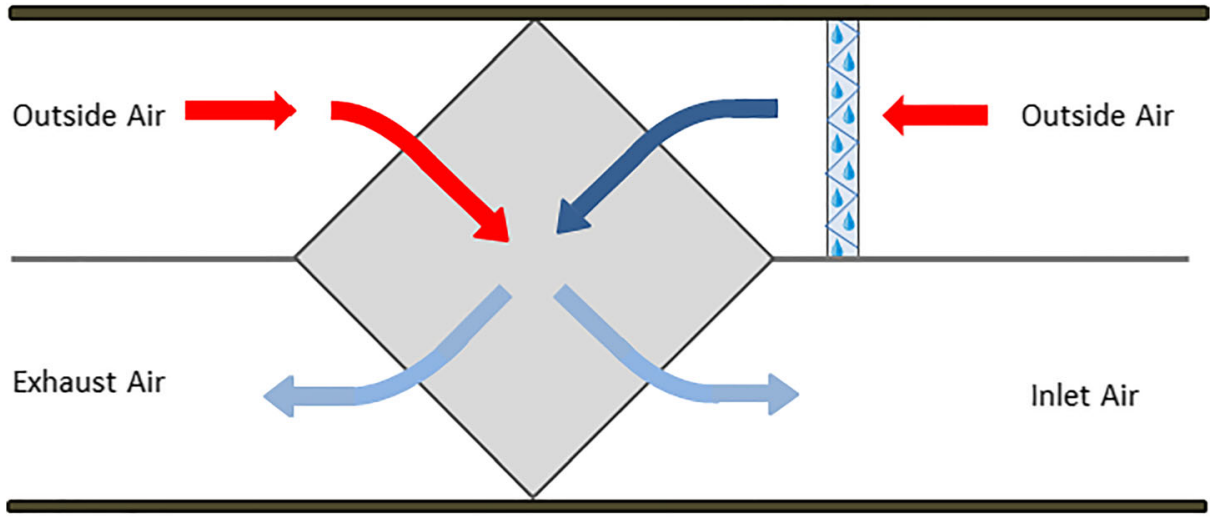

Heat Exchanger - HE

Fig. 1 Schematic diagram of an air treatment by indirect evaporative cooling CPHE: cooling pads (CP) combined with a regenerative heat exchanger (HE)

features of the soil, and the geometry of the tubes (Bisoniya et al. 2014; Ozgener 2011; Tzaferis et al. 1992). All calculations were performed with the number of transfer unit (NTU) method (De Paepe and Janssens 2003; Mihalakakou et al. 1995; Tzaferis et al. 1992), which describes the modification as an asymptotic approach of the air temperature to the undisturbed soil temperature at the depths of the earth tubes. The calculation of the model parameters for the sensible and latent heat transfer can be found in detail in Vitt et al. (2017).

\subsubsection{Reduction of stocking density SD during summer season}

To reduce the sensible heat load during the warm season, the stocking density was reduced by assuming a smaller number of pigs inside a section of the livestock building at the beginning for those fattening periods, which begin between the 57th and the 119th day of the year (approximately the 1st of March to the 30th of April). Two scenarios were calculated with a reduction to $80 \%$ (SD80\%) and 60\% (SD60\%) compared with REF.

\subsubsection{Doubling of the summer ventilation rate VENT}

To reduce the difference between the inlet air temperature (outdoor temperature) and indoor air temperature due to the sensible heat release of the animals, the maximum ventilation rate was doubled from 107 to $214 \mathrm{~m}^{3} \mathrm{~h}^{-1}$, according to the recommendations by the MWPS-32 (1990) for hot weather. The doubling can also be interpreted as a reduction in the animal density by $50 \%$ (SD50\%) compared with REF, with the advantage that the number of animals can be kept constant over the year.

\subsubsection{Inversion of the diurnal feeding and resting pattern SHIFT}

Introducing a shift of the feeding and resting time pattern by approximately half a day, the maximum of the outdoor temperature coincides with the resting time. The time shift of $10 \mathrm{~h}$ was determined by the diurnal temperature variation of heat days (daily maximum $>30^{\circ} \mathrm{C}$ ), as 
shown in Fig. 2. The modification of the time pattern can be achieved by the light regime inside the building, which means that the windows have to have blinds, and only artificial light has to be used for the feeding time during the night.

\section{Results}

This paper focuses on the thermal climate inside the building and the related heat stress parameters calculated for the reference system REF and the seven AMs.

The annual maximum of the heat stress parameters was found in 2003 and 2015, and the minimum appears mostly in 1984 as well as in some other years $(1985,1989,1990,1996$, and 1997) (Table 3). We selected 2003 as one of the hottest years in the period 1981 to 2017 to present daily maximum values for REF and the seven AMs between April and August (Fig. 3). The highest values were calculated for REF. The AMs without air treatment (SHIFT, SD80\%, SD60\%, and VENT) lie close to REF and show limited effectiveness. The two air treatment scenarios with adiabatic cooling (CP (purple) and CPHE (pink)) show a better performance. The best cooling performance by far was reached by the EAHE (light blue).

The efficacy of the AMs (exceedance frequency $P_{x}$ and area under the curve $A_{x}$ ) is presented by the thresholds of the indoor air temperature $X_{T}=25{ }^{\circ} \mathrm{C}$ (Fig. 4) and the

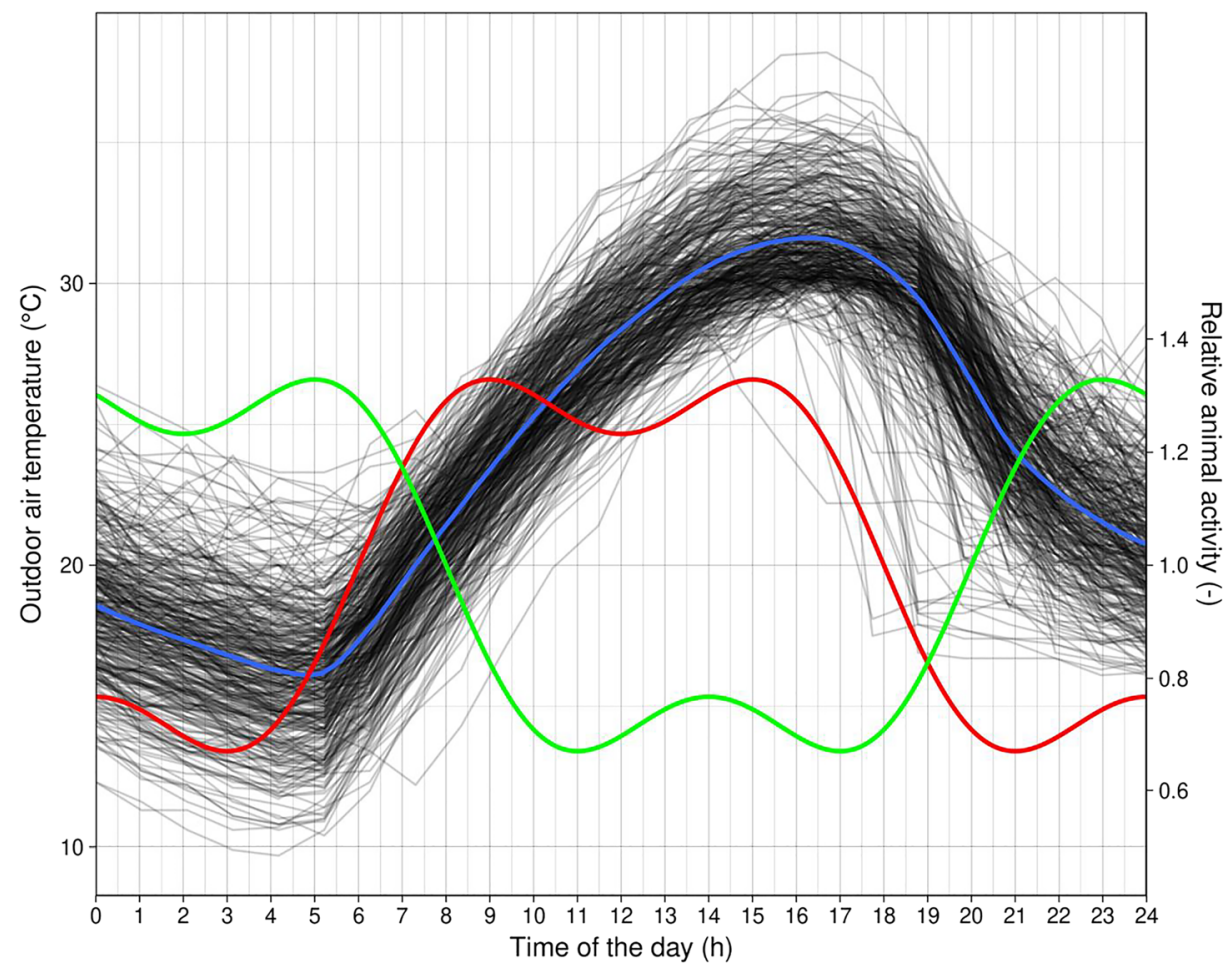

Fig. 2 Diurnal variation of the temperature of heat days (daily maximum $>30{ }^{\circ} \mathrm{C}$; blue line: average) between 1981 and 2017 and the time pattern of the relative animal activity for the conventional reference system REF, which describes the feeding and resting time schedule (red line) and the pattern by a shift of $10 \mathrm{~h}$ (green line) 


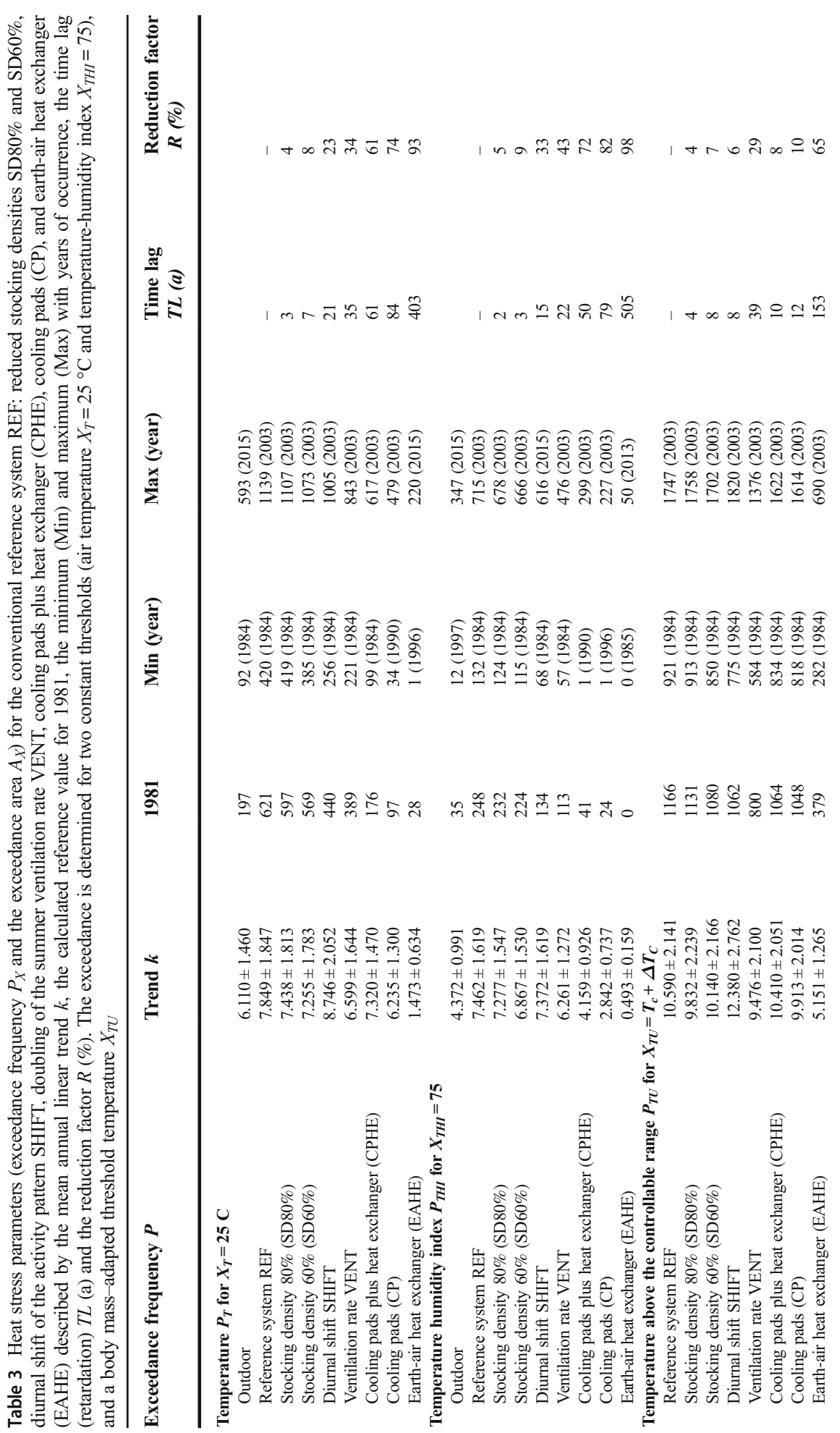




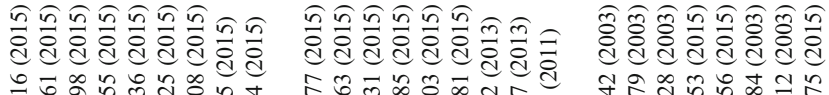

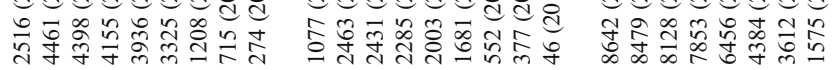

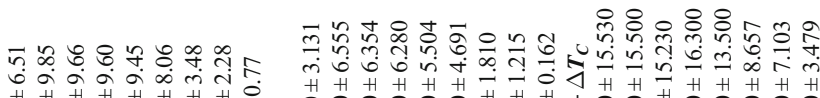
H H H H H H

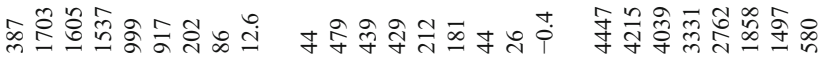

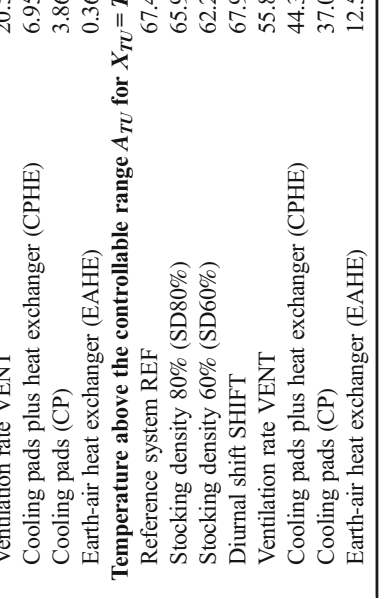




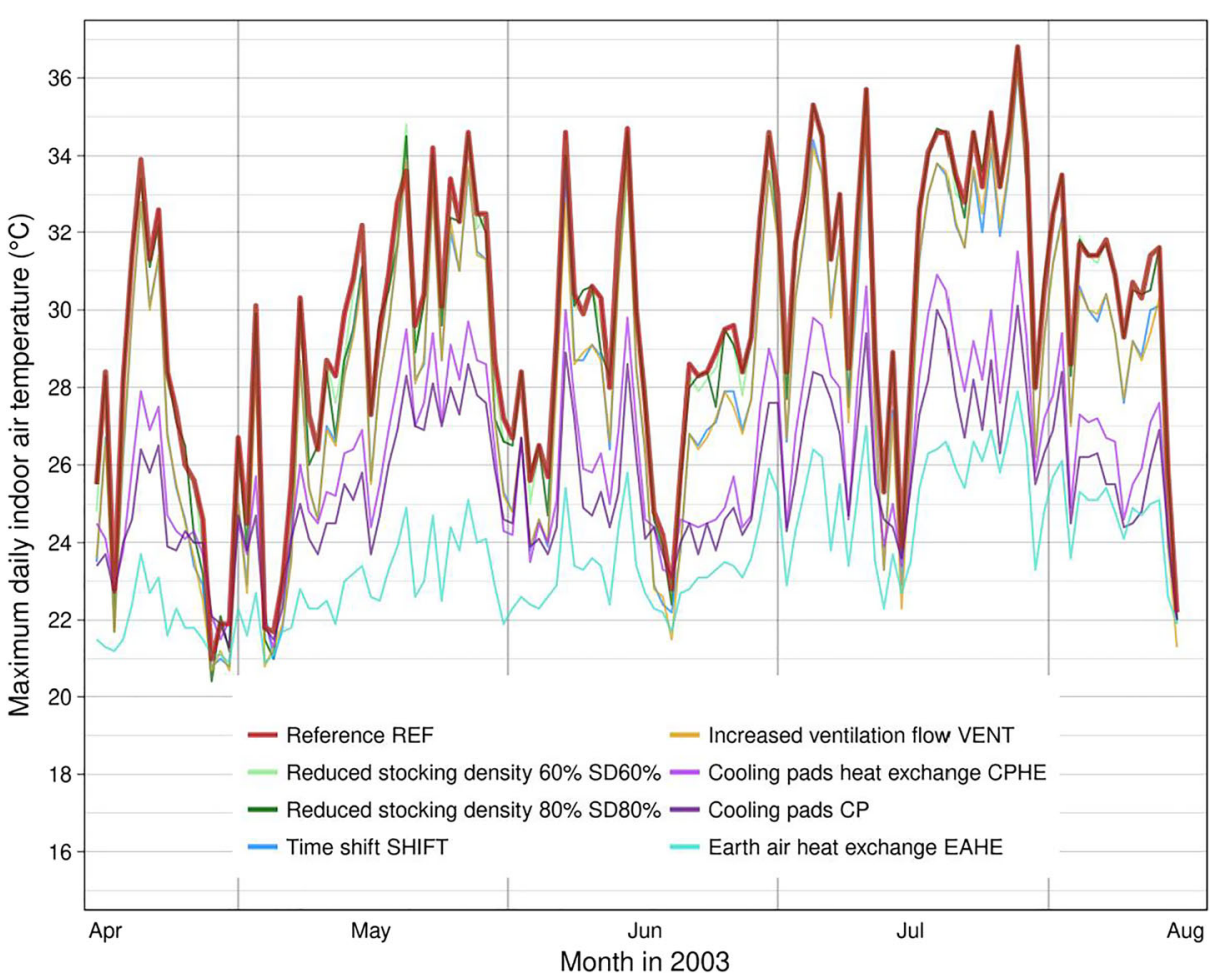

Fig. 3 Daily maximum of the indoor air temperature $T$ between April and August 2003 for the conventional reference system REF and the seven adaptation measures AM: (1) cooling pads (CP); (2) cooling pads with heat exchanger (CPHE); (3) earth-air heat exchanger (EAHE); (4) inverted diurnal time pattern SHIFT; (5 and 6) reduced stocking density by $80 \%$ (SD80\%) and 60\% (SD60\%); and (7) doubling of the maximum ventilation rate VENT

temperature-humidity index $X_{T H I}=75$ (Fig. 5) as constant heat stress parameters and the body mass-adapted heat stress parameter $X_{T U}$ (Fig. 6).

The temporal trend of REF is used as a baseline for the selected AMs. The relative linear trend of exceedance frequency $P_{X}$ and exceedance area $A_{X}$ is positive for all heat stress parameters, showing a mean relative annual change for the indoor climate of $1.3 \%\left(P_{T}\right)$ and $3.0 \%\left(P_{T H I}\right)$ per year for the exceedance frequency $P_{X}$ and $2.4 \%\left(A_{T}\right)$ and $6.4 \%\left(A_{T H I}\right)$ for the exceedance area $A_{X}$. This shows that the heat stress is not only caused by the temperature increase but is also due to the increase of the humidity inside the livestock building. The humidity-related heat stress parameters $P_{T H I}$ and $A_{T H I}$ are by a factor of 2 higher than the temperature-related heat stress parameters $P_{T}$ and $A_{T}$ (Mikovits et al. 2019). For the body mass-adapted heat stress parameters $P_{T U}$ and $A_{T U}$, the relative trend is $0.9 \%$ and $1.5 \%$ per year, respectively.

The slope of the regression lines of the exceedance area $A_{X}$ is approximately two times higher than for the exceedance frequency $P_{X}$. The starting points of the regression lines (1981) show the highest values for REF. Therefore, the regression lines (Figs. 4, 5, and 6) are almost parallel, ranked by the efficacy of the AMs.

The performances of the seven AMs were analysed by the reduction factor $R$, which is related to the heat stress parameters of REF (Table 3). The reduction factor 
a

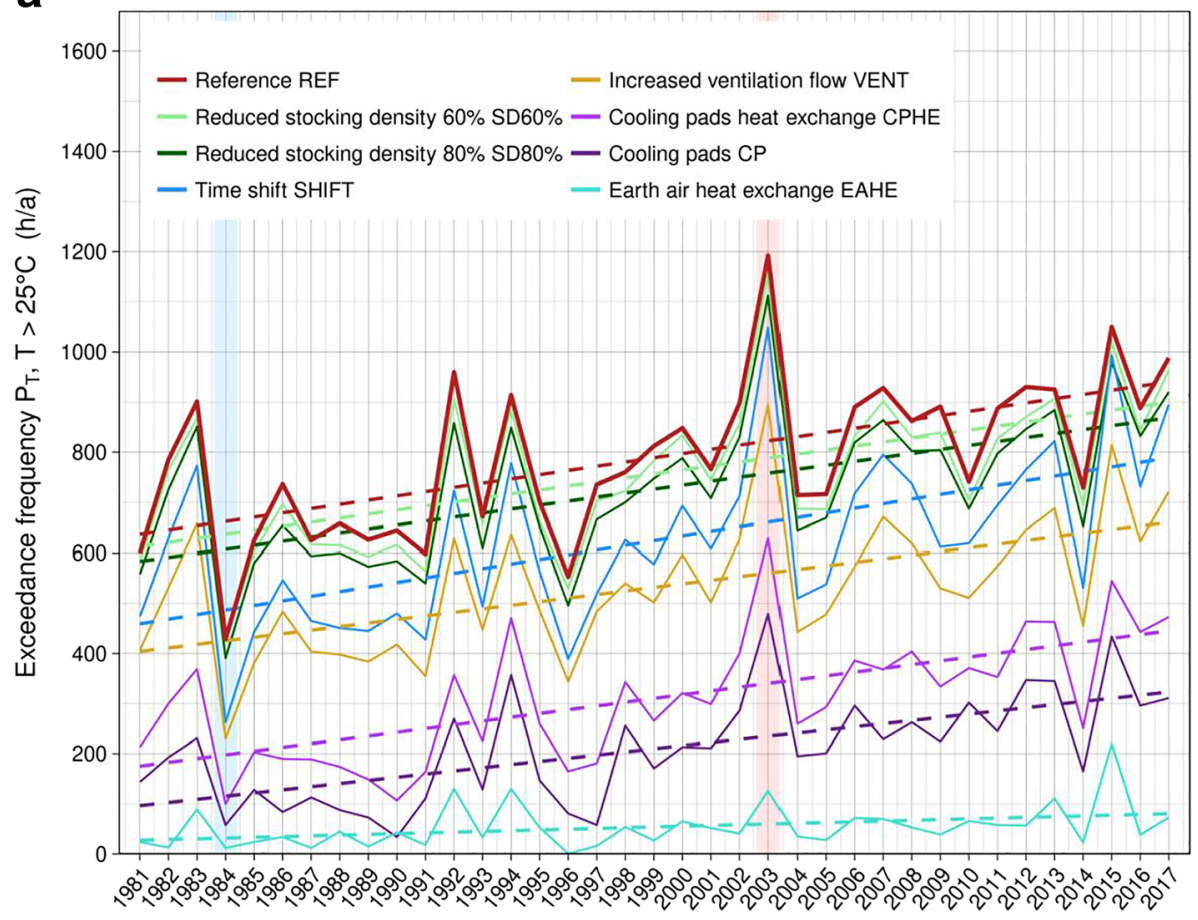

Year

b

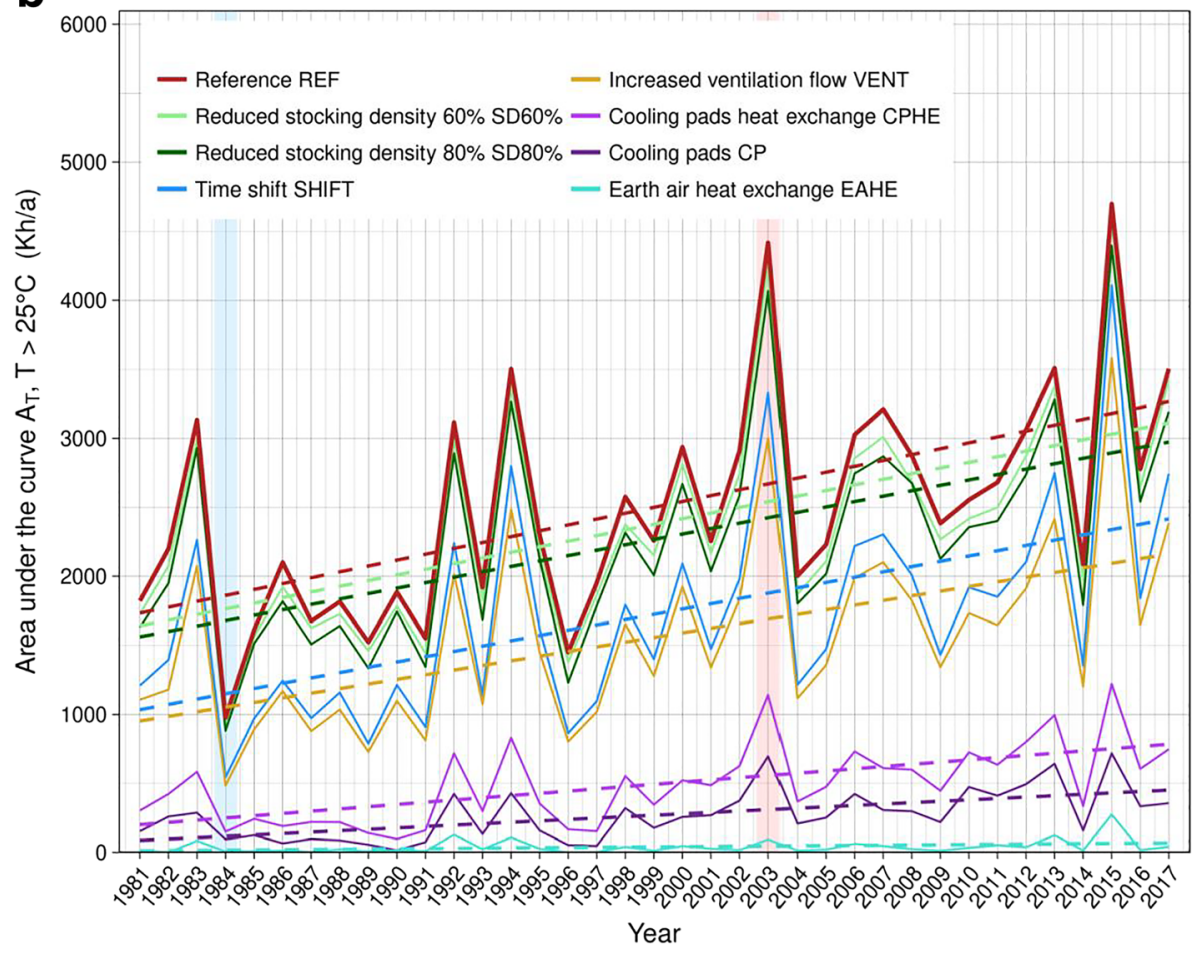


Fig. 4 Annual exceedance frequency $P_{T}$ (a) and exceedance area $A_{T}$ (b) for the threshold of the indoor air temperature $X_{T}=25{ }^{\circ} \mathrm{C}$ determined for the conventional reference system REF and the seven adaptation measures AM: reduced stocking densities SD80\% and SD60\%, diurnal shift of the activity pattern SHIFT, doubling of the summer ventilation rate VENT, the cooling pads plus heat exchanger (CPHE), cooling pads (CP), and earth-air heat exchanger (EAHE). The linear regressions are shown by dashed lines

was calculated for all six heat stress parameters. The AMs were ranked in ascending order, according to the reduction factor $R$, as a measure of the performance, based on the exceedance area $A_{X}$ (lower part of Table 3). The weakest performance was calculated for the reduction of the stocking densities SD80\% and SD60\%, with a reduction factor of $R$ below $11 \%$ for all heat stress parameters. The reduction factors for SHIFT and VENT are between $6\left(P_{T U}\right)$ and 51\% $\left(A_{T H I}\right)$. The highest heat stress reduction of more than $50 \%$ for most of the heat stress parameters was found for the air treatment devices (CP, CPHE, and EAHE). For the body mass-adapted heat stress parameter $P_{T U}$, the reduction factor is distinctly lower (between 8 and $65 \%$ ). The second highest reduction factor was determined for the doubling of the ventilation rate VENT with $29 \%$. For the heat stress parameter $A_{T U}$, the reduction factor of the AMs is in the same range and order as for the other heat stress parameters.

The linear slope of the temporal trend $k$ was used to evaluate the resilience against global warming of the livestock system (Table 3). The resilience can be determined twofold, first in relation to the outdoor situation and second in comparison with REF. A lower resilience of the livestock system results in a steeper slope of the heat stress parameter for a certain AM compared with the outdoor situation or with REF. For the four constant thresholds, the resilience of REF and for all AMs without air treatment (SD80\%, SD60\%, SHIFT, and VENT) shows a steeper slope (lower resilience) compared with the outside situation. This means that the temporal trend caused by global warming (outdoor) will worsen the heat stress inside the livestock system (Mikovits et al. 2019). The three AMs with air treatment (CPHE, CP, and EAHE) show a lower slope, which means that these systems increase the resilience for the livestock system in comparison with REF and are able to compensate the impact of global warming. The cooling efficacy of the three air treatment devices is high enough to keep the temperature inside the livestock system lower compared with the temperature outside, even though the animals are causing a high sensible heat load. All seven AMs improve the resilience of the livestock system against global warming. Nevertheless, the three air preparation AMs show a much better performance, compared with the other AMs.

The time lag $T L$ is a measure for the gain in time which can be expected on the basis of the reduction factor $R$ and the linear trend $k$ of the heat stress parameters. A $T L=10$ a means that in the year 1991, 10 years after the reference year 1981, the expected mean heat stress for a certain AM will be the same as the REF in 1981 (Table 3). For the two AMs with varying stocking density, i.e., SD60\% and SD80\%, the gain in time lies below $7 \mathrm{a}$, which is not a major benefit compared with REF. Using SHIFT and VENT, a gain in time between $8\left(P_{T U}\right)$ and 35 a $\left(P_{T U}\right)$ can be expected, whereas the three air treatment devices (CP, CPHE, and EAHE) show a time gain of more than 50 a, with the exception of one heat stress parameter $P_{T U}$. 


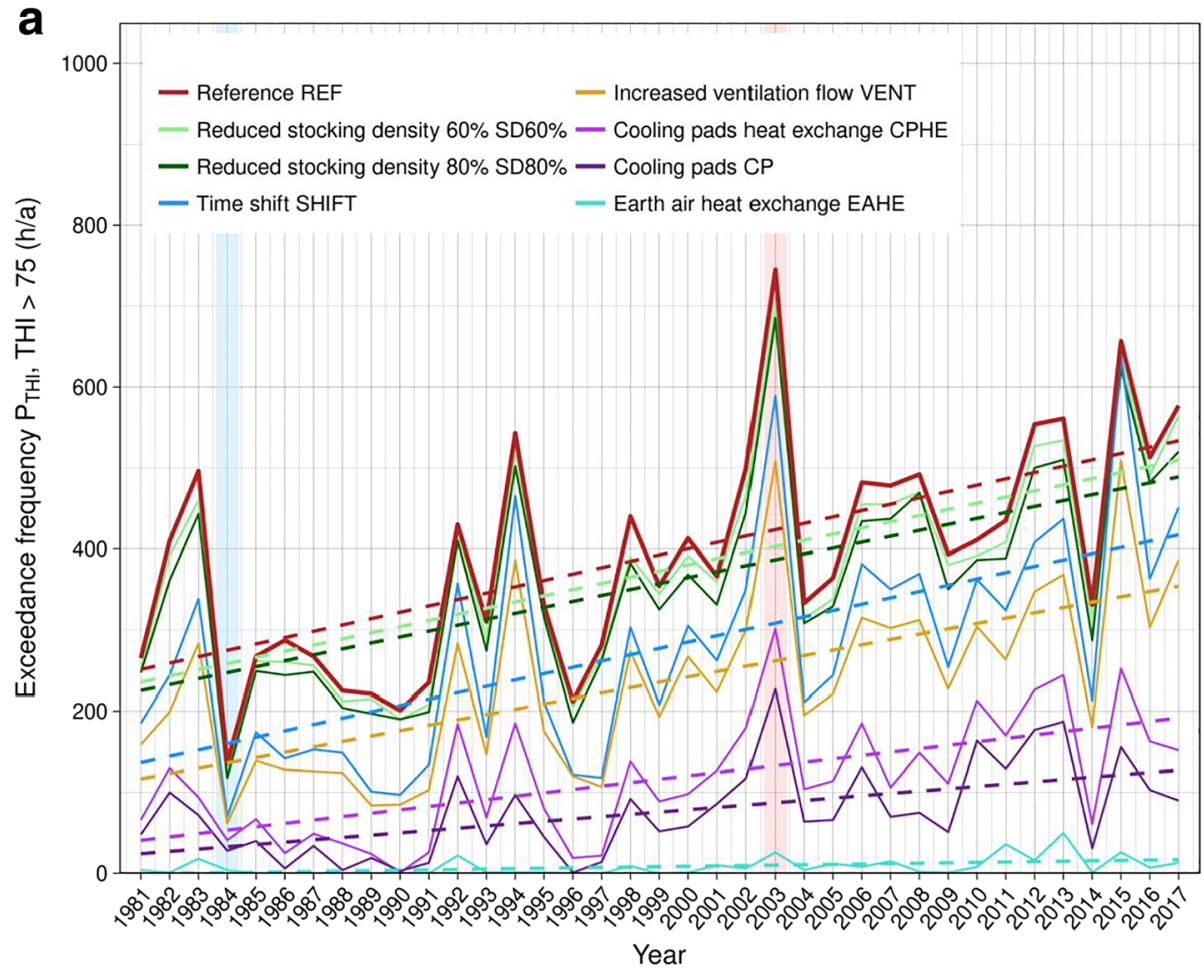

b

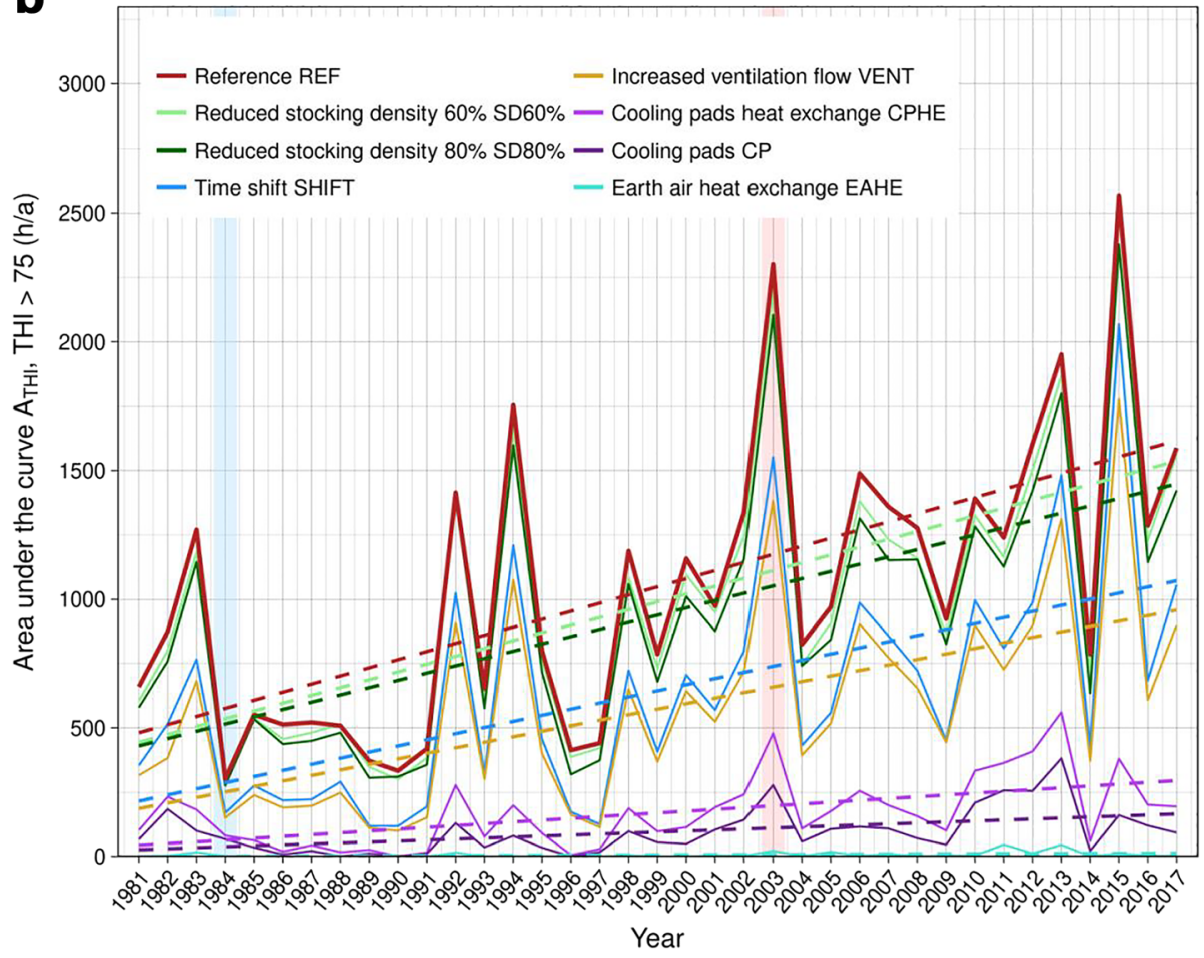


Fig. 5 Annual exceedance frequency $P_{T}$ (a) and exceedance area $A_{T}$ (b) for the threshold of the temperaturehumidity index $X_{T H I}=75$ determined for the conventional reference system REF and the seven adaptation measures AM: reduced stocking densities SD80\% and SD60\%, diurnal shift of the activity pattern SHIFT, doubling of the summer ventilation rate VENT, the cooling pads plus heat exchanger (CPHE), cooling pads (CP), and earth-air heat exchanger (EAHE). The linear regressions are shown by dashed lines

\section{Discussion}

The model calculations of a livestock confinement building for fattening-growing pigs show that heat stress is a major concern. For pig farmers, economic losses due to heat stress can result in a reduction of feed efficiency, growth rate, egg and meat production, semen quality as well as infertility, reproductive disorders, or increasing death rates (Dittrich et al. 2017; Renaudeau et al. 2012; St-Pierre et al. 2003).

Currently, approximately $50 \%$ of the world's pork production and $70 \%$ of the world's poultry meat production originate from industrial systems (Steinfeld et al. 2006). In the future, pig stocks in intensified systems are estimated to increase 3.0 to 3.5 times, broilers 4.4 to 5.0 times, and layers 2.0 to 2.4 times (Fischer et al. 2006). With respect to the environmental impact of livestock, the industrial systems have the advantage that they show a lower $\mathrm{CO}_{2}$ footprint per unit of product (e.g., due to an increase of the feed conversion ratio) (Audsley et al. 2010), a better management of other pollutants (ammonia and odourous substances) (Schauberger et al. 2018), and a greater efficiency in energy demand (quotient of energy input to output) for industrial systems for broiler chickens (4.5) and pigs (9.3) compared with beef cattle (13.3 to 40 depending on diet and age) (Misztal 2017). Past structural developments and investments in the livestock industry indicate the larger economic profitability of industrial systems and powerful economies of scale as well. This shows the increasing demand for investigations in the field of livestock confinement buildings, especially since most of the literature explores climate impacts on grazing animals and not on livestock in such industrial systems (Weindl et al. 2015).

The advantages of the presented modelling approach in comparison with measurements are manifold: (1) the model can be applied to other sites by the use of corresponding meteorological datasets, (2) near future scenarios can be assessed by the extrapolation of the linear trend in a long time series (e.g., 1981 to 2017) as robust predictions (Hendry and Pretis 2016), (3) future climate scenarios can be calculated by datasets on an hourly basis (e.g., van Leuken et al. 2016), (4) case studies can be performed for combinations of AMs to optimise the indoor climate by the use of heat stress parameters as a cost function, (5) optimisation of the design values (e.g., for the EAHE) can help improve the efficacy relative to the climatic situation for a certain site, (6) future developments of system parameters can be considered (e.g., market demand of heavier pigs at slaughter), and (7) heat stress can be quantified in comparison with qualitative assessments (e.g., Derner et al. 2017).

The model calculations were performed for a site in Austria located in Central Europe. The climate is within class $\mathrm{Cfb}$ (temperate oceanic climate) of the Köppen-Geiger climate classification, which is representative of large areas in Central Europe, excluding the Alps. The pig density (Robinson et al. 2011, 2014) and farm density (Marquer 2010) show the highest values for the $\mathrm{Cfb}$ climate class as well. This agreement between climate class $\mathrm{Cfb}$ and animal density can also be found for North America and Asia (predominantly China). Therefore, the evaluation of the AMs performed for a site in Austria can be used as an educated guess for 


\section{2}

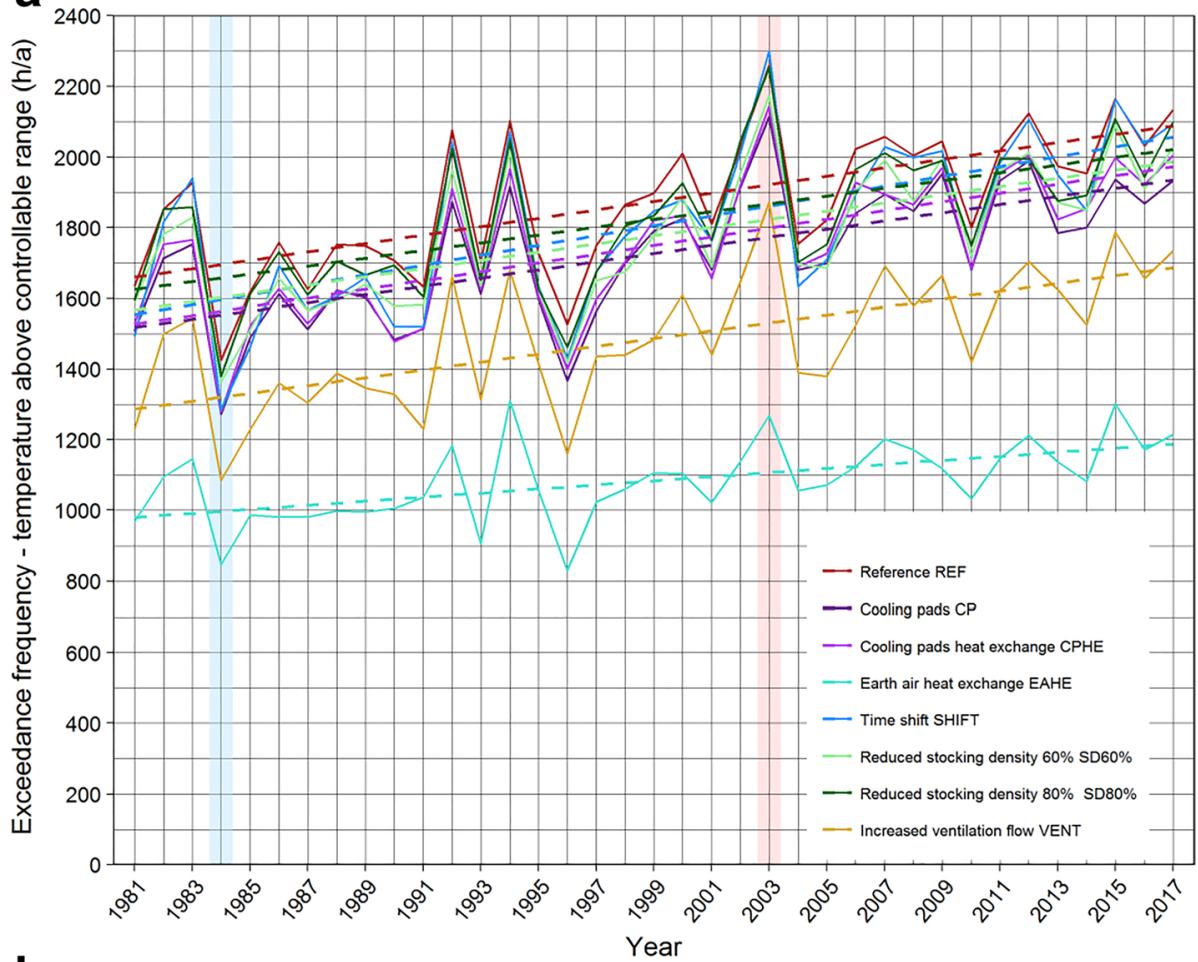

b

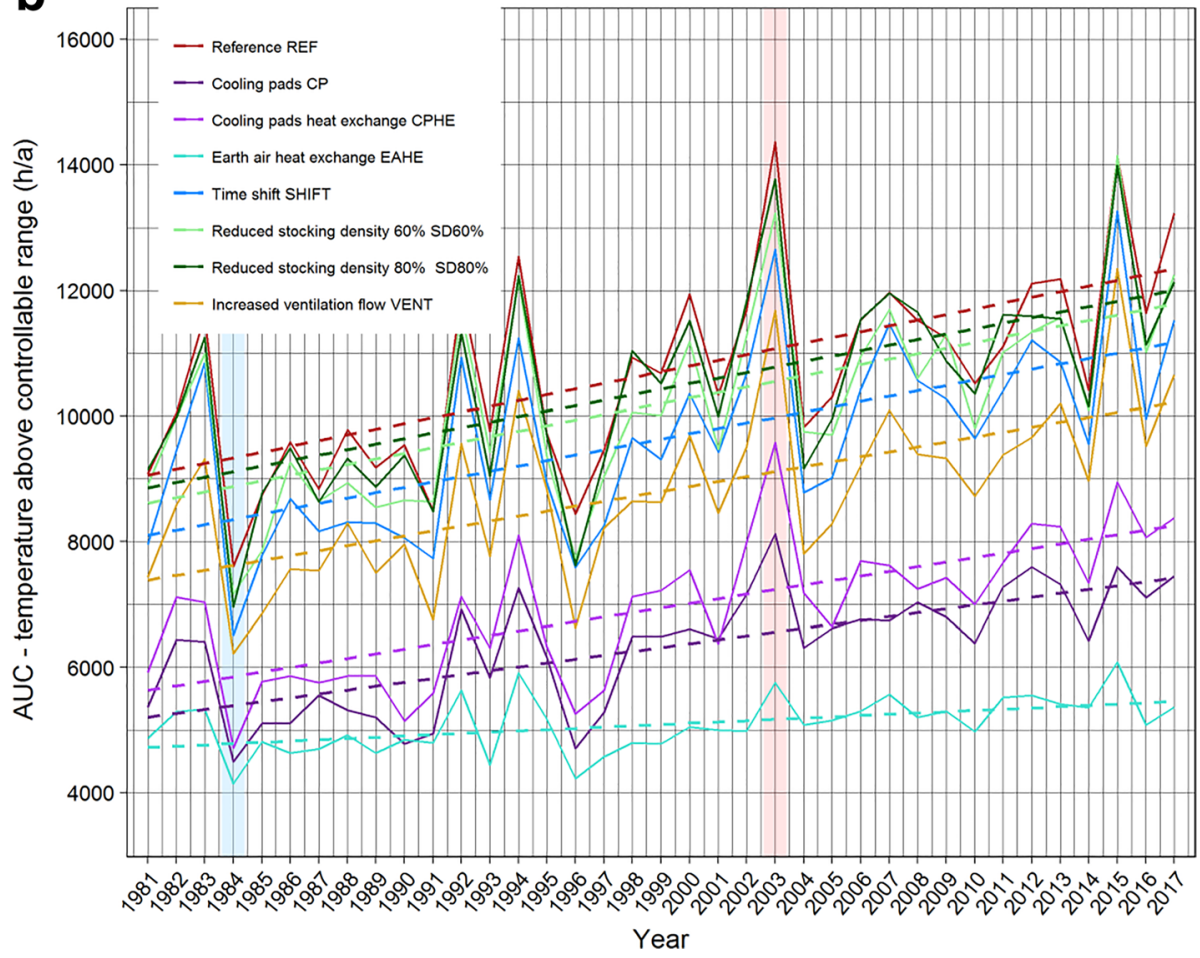


Fig. 6 Annual exceedance frequency $P_{T}$ (a) and exceedance area $A_{T}$ (b) for the threshold of the controllable temperature range $X_{T U}=T_{\mathrm{c}}+\Delta T_{\mathrm{C}}$, depending on the set point temperature of the ventilation control unit $T_{\mathrm{c}}$, which is related to the body mass $m$ of the pigs between 16 and $20{ }^{\circ} \mathrm{C}$ and the bandwidth of the control unit $\Delta T_{\mathrm{C}}$, determined for the conventional reference system REF and the seven adaptation measures AM: reduced stocking densities SD80\% and SD60\%, diurnal shift of the activity pattern SHIFT, doubling of the summer ventilation rate VENT, the cooling pads plus heat exchanger (CPHE), cooling pads (CP), and earth-air heat exchanger (EAHE). The linear regressions are shown by dashed lines

most areas where pork production is performed in industrial systems with livestock confinement buildings. Because the simulation model is driven by meteorological data of a certain site, the adaptation can easily be performed.

The occurrence of heat stress is caused not only by the variability of the meteorological parameters but also by a distinct temporal trend caused by global warming. For the years 1981 to 2017 , the pig-related heat stress parameters show a relative increase of 0.9 to $6.3 \%$ per year (Mikovits et al. 2019). The resilience of the indoor climate of the reference system without AMs is distinctly lower compared with the meteorological values outdoor. This shows the necessity of using simulation models for the thermal indoor climate of livestock confinement buildings instead of using the meteorological parameters for the outdoor situation.

Therefore, the performance of several AMs to reduce or avoid thermal stress was investigated. The performance of these AMs was evaluated by the reduction factor and the time gain, which help to overcome the growing occurrence of heat stress in the future. Even if stationarity cannot be assumed for global warming, the extrapolation of the trend can be used as a robust prediction for the near future (Hendry and Pretis 2016).

The model calculations reveal two groups of AMs. The AMs of the first group are more related to livestock management. Most of these measures will need lower investment costs. The shift of the time pattern SHIFT can be established without investment costs; only running costs are increased due to the shift of the working hours to the more expensive night time. Even if the reduction of the stocking densities SD80\% and SD60\% does not require investments, if it reduces variable costs, the opportunity costs of forgone revenues can be high. The reduction of the animal density can only be selected if the farmer has no contractual commitments to raise a certain number of pigs. By doubling the ventilation rate VENT, an equivalent effect of reducing the animal density to $50 \%$ can be achieved with the advantage that the number of animals which are produced does not change throughout the year. Compared with SD80\% and SD60\% as well as SHIFT, the doubling of the ventilation rate VENT needs additional investment costs by doubling the capacity of the fans.

The second group includes energy-saving air preparation systems which need investments and will provoke additional operating costs as well (Vitt et al. 2017). The three air treatment devices CP, CPHE, and EAHE are compatible with current livestock housing systems. They can be seen as incremental AMs to avoid disruptions of the current livestock systems in the future (Kates et al. 2012). The results of the air preparation devices show that the EAHE is the most efficient air treatment device. It eliminates heat stress, depending on the selected heat stress parameter, by 90 to $100 \%$, and can also be used during wintertime to increase the inlet air temperature. This means that the ventilation rate can be increased, thereby improving the indoor air quality, especially during wintertime. CP will reduce heat stress by 74 to $92 \%$, with the disadvantage that the inlet air will be moistened. This can increase the heat stress if THI is used. CPHE can avoid this shortcoming at the expense of a limited heat stress reduction between 61 and $86 \%$ and higher investment costs because this AM uses not only CPs but also 
a regenerative or recuperative heat recovery system (Porumb et al. 2016a, b). Nevertheless, the profitability of management-based AMs and these air preparation AMs has to be investigated.

All AMs can be divided into groups relative to their costs, complexity, knowledge requirements of the farmers, and the time scale of the implementation (Holzkämper 2017). AMs related to management can be applied for the short term, such as SD60\% and SD80\% and SHIFT. They can be seen as incremental responses and are often chosen autonomously by the farmers in response to observed changes and based on local knowledge and experience. These management measures can be applied on a short-term basis from year to year and need only limited investments. The second group are long-term adaptations with transformative response that require strategic planning. Planning for new livestock buildings requires foreseeing options for the eventual implementation of potential AMs. Therefore, the data for the design and planning of AMs have to be known early enough for farmers, consultants, and veterinarians to ensure a high level of sustainability in livestock production (Walker et al. 2013). In this context, air treatment devices are long-term structural measures and investments. The lead time and the lifetime of these measures determine their economic profitability (Dittrich et al. 2017).

\section{Conclusions}

Global warming has negatively impacted livestock kept in confined buildings during the last three decades and will do so in the future according to the trend analysis in this study. Robust measures of heat stress inside livestock buildings can only be quantified by a simulation model of the indoor climate over longer time periods. Compared with the outdoor rearing of farm animals, the indoor situation shows a lower resilience. By the use of adaptive measures, heat stress can be reduced, and resilience can be increased. Energy-saving air preparation devices especially can reduce heat stress in the range up to $100 \%$. Other measures for adaptation, such as the reduction of the stocking density and the shift of the activity pattern of the animals to night time, are less effective.

Funding information Open access funding provided by University of Veterinary Medicine Vienna. The project PiPoCooL Climate change and future pig and poultry production: implications for animal health, welfare, performance, environment and economic consequences was funded by the Austrian Climate and Energy Fund within the framework of the Austrian Climate Research Program (ACRP8 - PiPoCooL - KR15AC8K12646).

\section{Compliance with ethical standards}

Conflict of interest The authors declare that they have no conflict of interest.

Open Access This article is distributed under the terms of the Creative Commons Attribution 4.0 International License (http://creativecommons.org/licenses/by/4.0/), which permits unrestricted use, distribution, and reproduction in any medium, provided you give appropriate credit to the original author(s) and the source, provide a link to the Creative Commons license, and indicate if changes were made.

\section{References}

ASHRAE (2008) Air-to-air energy recovery (chapter 25). ASHRAE handbook-HVAC systems and equipment. American Society of Heating, Refrigerating and Air-Conditioning Engineers Inc., Atlanta, USA 
ASHRAE (2009) Evaporative air-cooling equipment (chapter 40). ASHRAE handbook-HVAC systems and equipment. American Society of Heating, Refrigerating and Air-Conditioning Engineers Inc., Atlanta, USA

Audsley E, Brander M, Chatterton JC, Murphy-Bokern D, Webster C, Williams AG (2010) How low can we go? An assessment of greenhouse gas emissions from the UK food system and the scope reduction by 2050. Report for the WWF and Food Climate Research Network

Bisoniya TS, Kumar A, Baredar P (2014) Study on calculation models of earth-air heat exchanger systems. Journal of Energy Volume 2014, ID 859286: 1-15

Bracke MBM (2011) Review of wallowing in pigs: description of the behaviour and its motivational basis. Appl Anim Behav Sci 132:1-13

Bull R, Harrison P, Riskowski G, Gonyou H (1997) Preference among cooling systems by gilts under heat stress. J Anim Sci 75:2078-2083

Cabezon FA, Schinckel AP, Stwalley Iii RM (2017) Thermal capacity of hog-cooling pad. Appl Eng Agric 33:891

Chimani B, Heinrich G, Hofstätter M, Kerschbaumer M, Kienberger S, Leuprecht A, Lexer A, Peßenteiner S, Poetsch MS, Salzmann M, Spiekermann R, Switanek M, Truhetz H (2016) ÖKS15 - Klimaszenarien für Österreich. Daten, Methoden und Klimaanalyse. Report, Vienna

CIGR (1989) 2nd report of working group on climatization of animal houses. Commission International du Genié Rural (CIGR) State University of Ghent, Ghent

Cooper K, Parsons DJ, Demmers T (1998) A thermal balance model for livestock buildings for use in climate change studies. Journal of Agricultural and Engineering Research 69:43-52

de Mello JLM, Berton MP, de Cassia Dourado R, Giampietro-Ganeco A, de Souza RA, Ferrari FB, de Souza PA, Borba H (2017) Physical and chemical characteristics of the longissimus dorsi from swine reared in climatecontrolled and uncontrolled environments. Int. J. Biometeorol. 1-9

De Paepe M, Janssens A (2003) Thermo-hydraulic design of earth-air heat exchangers. Energy Build. 35:389397

Derner J, Briske D, Reeves M, Brown-Brandl T, Meehan M, Blumenthal D, Travis W, Augustine D, Wilmer H, Scasta D, Hendrickson J, Volesky J, Edwards L, Peck D (2017) Vulnerability of grazing and confined livestock in the Northern Great Plains to projected mid- and late-twenty-first century climate. Climatic Change: $1-14$

Dittrich R, Wreford A, Topp CFE, Eory V, Moran D (2017) A guide towards climate change adaptation in the livestock sector: adaptation options and the role of robust decision-making tools for their economic appraisal. Reg Environ Chang:1-12

Fehr R, Priddy K, McNeill S, Overhults D (1983) Limiting swine stress with evaporative cooling in the southwest. Transactions of the ASAE 26:542-0545

Fischer G, Ermolieva T, Ermoliev Y, Velthuizen Hv (2006) Agricultural development under risks and uncertainties. CSM'06, 20th Workshop on Complex Systems Modeling, August 28-30, 2006, IIASA, Laxenburg, Austria, Laxenburg, Austria

Gerber P, Steinfeld H, Henderson B, Mottel A, Opio C, Dijkman J, Falcucce A, Tempio G (2013) Tackling climate change through livestock. A global assessment of emissions and mitigation opportunities. Food and Agriculture Organization of the United Nations (FAO), Rome

Gosling SN, Bryce EK, Dixon PG, Gabriel KMA, Gosling EY, Hanes JM, Hondula DM, Liang L, Bustos Mac Lean PA, Muthers S, Nascimento ST, Petralli M, Vanos JK, Wanka ER (2013) A glossary for biometeorology. Int. J. Biometeorol.:1-32

Hatfield JL, Antle J, Garrett KA, Izaurralde RC, Mader T, Marshall E, Nearing M, Philip Robertson G, Ziska L (2018) Indicators of climate change in agricultural systems. Clim Chang:1-14

Hendry DF, Pretis F (2016) All change! The implications of non-stationarity for empirical modelling, forecasting and policy. Oxford Martin School Policy Paper Series, Forthcoming. Available at SSRN: https://ssrn. com/abstract=2898761

Holzkämper A (2017) Adapting agricultural production systems to climate change — what's the use of models? Agriculture 7:86

Huynh TTT, Aarnink AJA, Gerrits WJJ, Heetkamp MJH, Canh TT, Spoolder HAM, Kemp B, Verstegen MWA (2005) Thermal behaviour of growing pigs in response to high temperature and humidity. Appl Anim Behav Sci 91:1-16

Huynh TTT, Aarnink AJA, Truong CT, Kemp B, Verstegen MWA (2006) Effects of tropical climate and water cooling methods on growing pigs' responses. Livest Sci 104:278-291

Jeon J, Yeon S, Choi Y, Min W, Kim S, Kim P, Chang H (2006) Effects of chilled drinking water on the performance of lactating sows and their litters during high ambient temperatures under farm conditions. Livest Sci 105:86-93

Kates RW, Travis WR, Wilbanks TJ (2012) Transformational adaptation when incremental adaptations to climate change are insufficient. Proc Natl Acad Sci 109:7156-7161 
Kottek M, Grieser J, Beck C, Rudolf B, Rubel F (2006) World map of the Köppen-Geiger climate classification updated. Meteorol Z 15:259-263

Marquer P (2010) Pig farming in the EU, a changing sector. Statistics in focus Eurostat:1-12

Mihalakakou G, Santamouris M, Asimakopoulos D, Tselepidaki I (1995) Parametric prediction of the buried pipes cooling potential for passive cooling applications. Sol Energy 55:163-173

Mikovits C, Zollitsch W, Hörtenhuber SJ, Baumgartner J, Niebuhr K, Piringer M, Anders I, Andre K, HennigPauka I, Schönhart M, Schauberger G (2019) Impacts of global warming on confined livestock systems for growing-fattening pigs: simulation of heat stress for 1981 to 2017 in Central Europe. Int J Biometeorol 63: 221-230

Misztal I (2017) Breeding and genetics symposium: resilience and lessons from studies in genetics of heat stress. J Anim Sci 95:1780-1787

MWPS-32 (1990) Mechanical ventilating systems for livestock housing. Midwest Plan Service, Iowa State University, Ames p. 70

Olesen JE, Bindi M (2002) Consequences of climate change for European agricultural productivity, land use and policy. Eur J Agron 16:239-262

Ozgener L (2011) A review on the experimental and analytical analysis of earth to air heat exchanger (EAHE) systems in Turkey. Renew Sust Energ Rev 15:4483-4490

Pang Z, Li B, Xin H, Yuan X, Wang C (2010) Characterisation of an experimental water-cooled cover for sows. Biosyst Eng 105:439-447

Porumb B, Ungureșan P, Tutunaru LF, Şerban A, Bălan M (2016a) A review of indirect evaporative cooling operating conditions and performances. in sustainable solutions for energy and environment, EENVIRO YRC, Energy Procedia, Bucharest, Romania, pp. 452-460

Porumb B, Ungureșan P, Tutunaru LF, Șerban A, Bălan M (2016b) A review of indirect evaporative cooling technology. Energy Procedia 85:461-471

Renaudeau D, Collin A, Yahav S, De Basilio V, Gourdine JL, Collier RJ (2012) Adaptation to hot climate and strategies to alleviate heat stress in livestock production. Animal 6:707-728

Robinson T, Thornton P, Franceschini G, Kruska R, Chiozza F, Notenbaert A, Cecchi G, Herrero M, Epprecht M, Fritz S (2011) Global livestock production systems. Food and Agriculture Organization of the United Nations (FAO), Rome

Robinson TP, Wint GRW, Conchedda G, Van Boeckel TP, Ercoli V, Palamara E, Cinardi G, D’Aietti L, Hay SI, Gilbert M (2014) Mapping the global distribution of livestock. PLoS One 9:e96084

Rötter R, van de Geijn S (1999) Climate change effects on plant growth, crop yield and livestock. Clim Chang 43:651-681

Sax M, Van Caenegem L, Schick M (2012) Optimales Stallklima dank Wärmerückgewinnungsanlagen auch im Sommer. Agrar Forschung Schweiz 3:428-435

Schauberger G, Piringer M, Baumann-Stanzer K, Knauder W, Petz E (2013) Use of a Monte Carlo technique to complete a fragmented set of $\mathrm{H}_{2} \mathrm{~S}$ emission rates from a waste water treatment plant. Journal of Hazardous Materials 263:694-701

Schauberger G, Piringer M, Mikovits C, Zollitsch W, Hörtenhuber SJ, Baumgartner J, Niebuhr K, Anders I, Andre K, Hennig-Pauka I, Schönhart M (2018) Impact of global warming on the odour and ammonia emissions of livestock buildings used for fattening pigs. Biosystems Engineering 175:106-114

Schauberger G, Piringer M, Petz E (1999) Diurnal and annual variation of odour emission from animal houses: a model calculation for fattening pigs. Journal of Agricultural and Engineering Research 74:251-259

Schauberger G, Piringer M, Petz E (2000) Steady-state balance model to calculate the indoor climate of livestock buildings, demonstrated for fattening pigs. Int J Biometeorol 43:154-162

Silva BAN, Oliveira RFM, Donzele JL, Fernandes HC, Lima AL, Renaudeau D, Noblet J (2009) Effect of floor cooling and dietary amino acids content on performance and behaviour of lactating primiparous sows during summer. Livest Sci 120:25-34

St-Pierre NR, Cobanov B, Schnitkey G (2003) Economic losses from heat stress by US livestock industries. J Dairy Sci 86:E52-E77

Steinfeld H, Gerber P, Wassenaar T, Castel V, Rosales M, De Haan C (2006) Livestock's long shadow. FAO Rome

Thiers S, Peuportier B (2008) Thermal and environmental assessment of a passive building equipped with an earth-to-air heat exchanger in France. Sol Energy 82:820-831

Turnpenny JR, Parsons DJ, Armstrong AC, Clark JA, Cooper K, Matthews AM (2001) Integrated models of livestock systems for climate change studies. 2. Intensive systems. Glob Chang Biol 7:163-170

Tzaferis A, Liparakis D, Santamouris M, Argiriou A (1992) Analysis of the accuracy and sensitivity of eight models to predict the performance of earth-to-air heat exchangers. Energy and Buildings 18:35-43

van Leuken JPG, Swart AN, Droogers P, van Pul A, Heederik D, Havelaar AH (2016) Climate change effects on airborne pathogenic bioaerosol concentrations: a scenario analysis. Aerobiologia 32:607-617 
Vitt R, Weber L, Zollitsch W, Hörtenhuber SJ, Baumgartner J, Niebuhr K, Piringer M, Anders I, Andre K, Hennig-Pauka I, Schönhart M, Schauberger G (2017) Modelled performance of energy saving air treatment devices to mitigate heat stress for confined livestock buildings in Central Europe. Biosyst Eng 164:85-97

Walker W, Haasnoot M, Kwakkel J (2013) Adapt or perish: a review of planning approaches for adaptation under deep uncertainty. Sustainability 5:955

Weindl I, Lotze-Campen H, Popp A, Müller C, Havlík P, Herrero M, Schmitz C, Rolinski S (2015) Livestock in a changing climate: production system transitions as an adaptation strategy for agriculture. Environ. Res. Lett. 10:094021

Wilks DS (2011) Statistical methods in the atmospheric sciences. Academic press, San Diego

Zhang G, Bjerg BS (2017) Developments of thermal environment techniques of animal housing in hot climate-a review. In: Ni J-Q, Lim T-T, Wang C, Zhao L (eds) Animal environment and welfare - proceedings of international symposium. China Agriculture Press, Beijing, pp 375-384

Publisher's note Springer Nature remains neutral with regard to jurisdictional claims in published maps and institutional affiliations.

\section{Affiliations}

\section{Günther Schauberger ${ }^{1}$ - Christian Mikovits ${ }^{1}$ - Werner Zollitsch ${ }^{2}$ - Stefan J. Hörtenhuber $^{2}$ • Johannes Baumgartner ${ }^{3} \cdot$ Knut Niebuhr $^{3} \cdot$ Martin Piringer $^{4} \cdot$ Werner Knauder $^{4} \cdot$ Ivonne Anders ${ }^{5} \cdot$ Konrad Andre $^{5} \cdot$ Isabel Hennig-Pauka ${ }^{6} \cdot$ Martin Schönhart ${ }^{7}$}

1 Department of Biomedical Sciences, WG Environmental Health, Unit for Physiology and Biophysics, University of Veterinary Medicine, Veterinärplatz 1, Vienna, Austria

2 Division of Livestock Sciences, Department of Sustainable Agricultural Systems, University of Natural Resources and Life Sciences, Vienna, Austria

3 Institute of Animal Husbandry and Animal Welfare, University of Veterinary Medicine, Vienna, Austria

4 Department of Environmental Meteorology, Central Institute of Meteorology and Geodynamics, Vienna, Austria

5 Department for Climate Research, Central Institute of Meteorology and Geodynamics, Vienna, Austria

6 University Clinics for Swine, Department for Farm Animals and Veterinary Public Health, University of Veterinary Medicine, Vienna, Austria

7 Institute for Sustainable Economic Development, Department of Economics and Social Sciences, University of Natural Resources and Life Sciences, Vienna, Austria 